\title{
The effect of intracoronary thrombolysis with streptokinase on myocardial thallium distribution and left ventricular function assessed by blood-pool scintigraphy
}

\author{
M. L. Simoons, W. Wijns, K. Balakumaran, P. W. Serruys, M. van den Brand, P. Fioretti, \\ J. H. C. Reiber, P. Lie And P. G. Hugenholtz \\ Thoraxcenter, Erasmus University and University Hospital Dijkzigt, Rotterdam, The Netherlands
}

KEY WORDS: Myocardial infarction, streptokinase, thallium, left ventricular function.

In order to evaluate the effect of coronary recanalization in acute myocardial infarction, thallium scintigrams were made on admission in 23 patients in whom thrombolysis was attempted and in 27 patients treated conventionally. The scintigrams were repeated immediately after the procedure or after $3 \mathrm{~h}$ in the control group. No significant differences were apparent between the initial thallium uptake in treated patients or controls. Some degree of thallium redistribution occurred in 43 out of 50 patients. The degree of redistribution was greater in patients with open or recanalized arteries (redistribution 35\%, s.d. $24 \%$ of initial defect) than in patients in whom the artery remained occluded (17\%, s.d. $12 \%)$. No differences were apparent in six patients between the late scintigrams and a third series of images made after an additional injection of thallium. Global left ventricular function was analysed in 30 patients with anteroseptal infarction and in 35 patients with inferior wall infarction. Ejection fractions were lower in patients with anterior wall infarction. Between one and seven days after admission, ejection fractions were similar in patients with open or occluded arteries in pilot studies and in randomized patients with inferior wall infarction after thrombolysis or conventional treatment. In patients with anterior wall infarction, left ventricular ejection fraction after streptokinase (45\%, s.d. $7 \%)$ was greater than after conventional treatment $(38 \%$, s.d. $12 \%)$. Analysis of segmental left ventricular function suggests that this difference is due in part to the improvement of segmental function in the non-infarcted areas. No differences were observed between ejection fractions measured early (1-7 days) or late (10-20 days) after myocardial infarction.

The data show considerable overlap between patients treated with streptokinase and those treated conventionally. Further randomized trials are needed to determine whether thrombolysis in acute myocardial infarction does indeed result in permanent improvement of myocardial function.

Intracoronary administration of streptokinase within the first hours of myocardial infarction has been shown to recanalize an occluded coronary artery in approximately $80 \%$ of cases ${ }^{[1-3]}$. Several authors claim that re-opening of such occluded arteries reduces the size of myocardial infarction and thus improves myocardial function ${ }^{[2,4-6]}$. These reports have been based on small series in which patients with successful thrombolysis were compared with patients in whom the procedure failed. Such analysis carries considerable bias, since patients in whom

Received for publication 24 May 1982.

Requests for reprints to: M. L. Simoons, M. D., Coronary Care Unit, Erasmus University and University Hospital Dijkzigt, P.O. Box 1738, 3000 DR Rotterdam, The Netherlands. thrombolysis succeeded are not necessarily similar to those in whom the intervention failed. In this paper a comparison is made between patients treated either with streptokinase or by conventional methods in a coronary care unit. Thallium scintigrams and gated blood-pool studies were obtained in patients who participated in pilot studies and others who were entered in a randomized trial where intracoronary administration of streptokinase was compared with conventional treatment of myocardial infarction.

\section{Patient selection and methods}

A detailed description of the pilot studies on 
Table 1 Patient selection

\begin{tabular}{lcc}
\hline \multicolumn{1}{c}{ Patient series } & Thallium study & Blood-pool study \\
\hline & Pilot studies & \\
Streptokinase & 7 & 13 \\
Nitroglycerin/nifedipine & 3 & - \\
Urokinase & 2 & 10 \\
Refused intervention/ & 9 & \\
$\quad$ conventional treatment & Randomized study & 21 \\
& 11 & 18 \\
Streptokinase & 18 & 65 \\
Conventional treatment & 50 & \\
Total & & \\
\hline
\end{tabular}

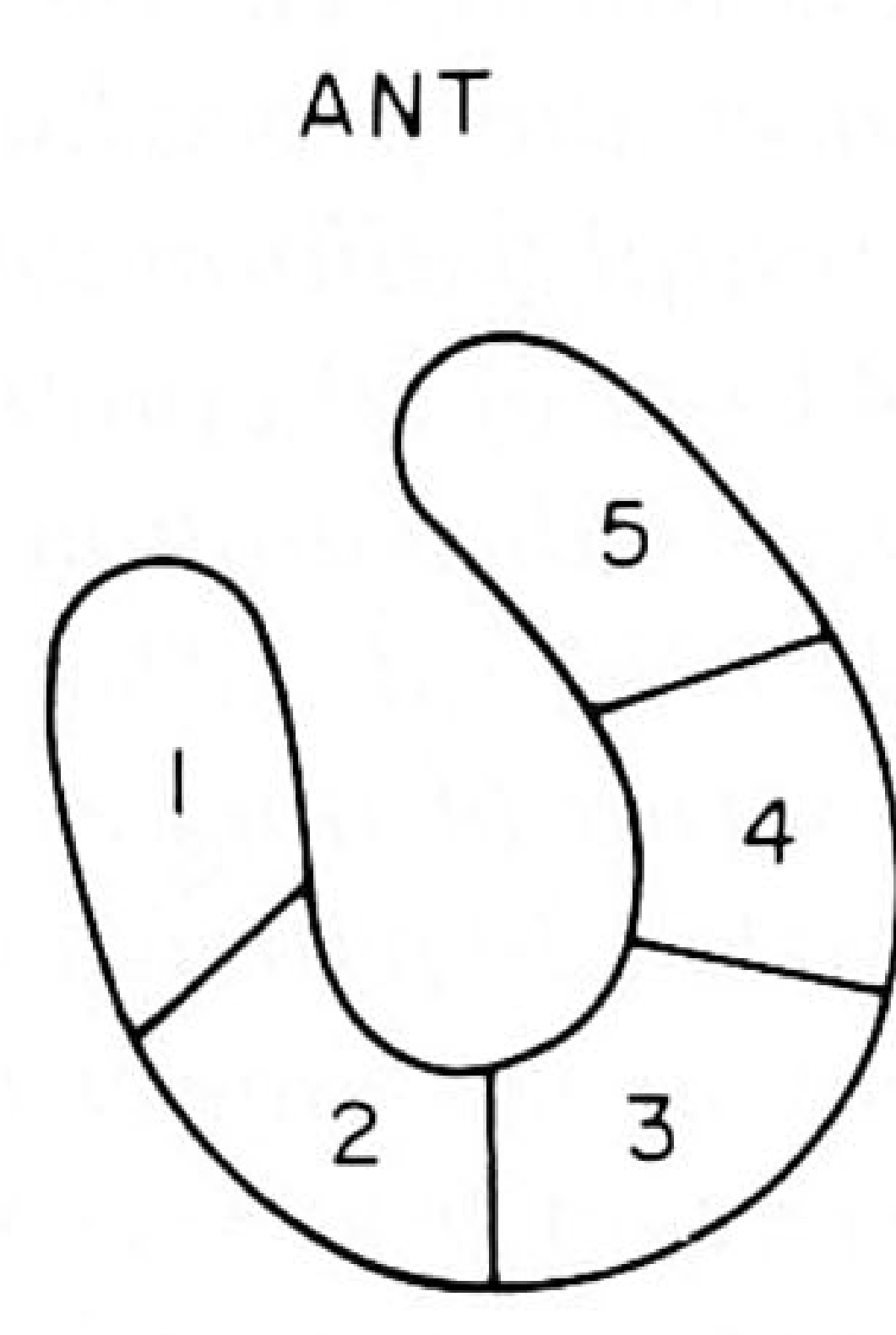

LAO $45^{\circ}$

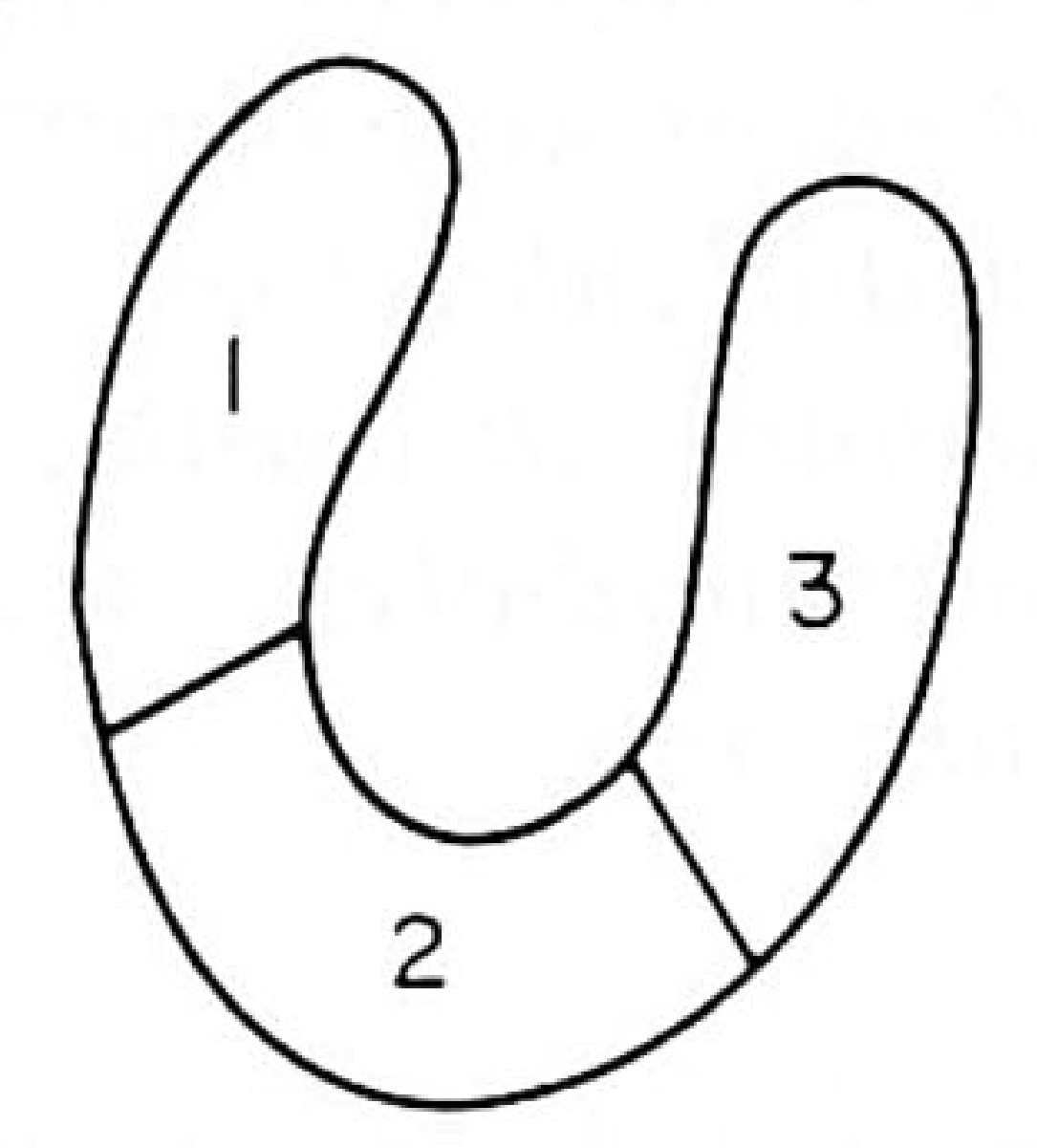

LAO $65^{\circ}$

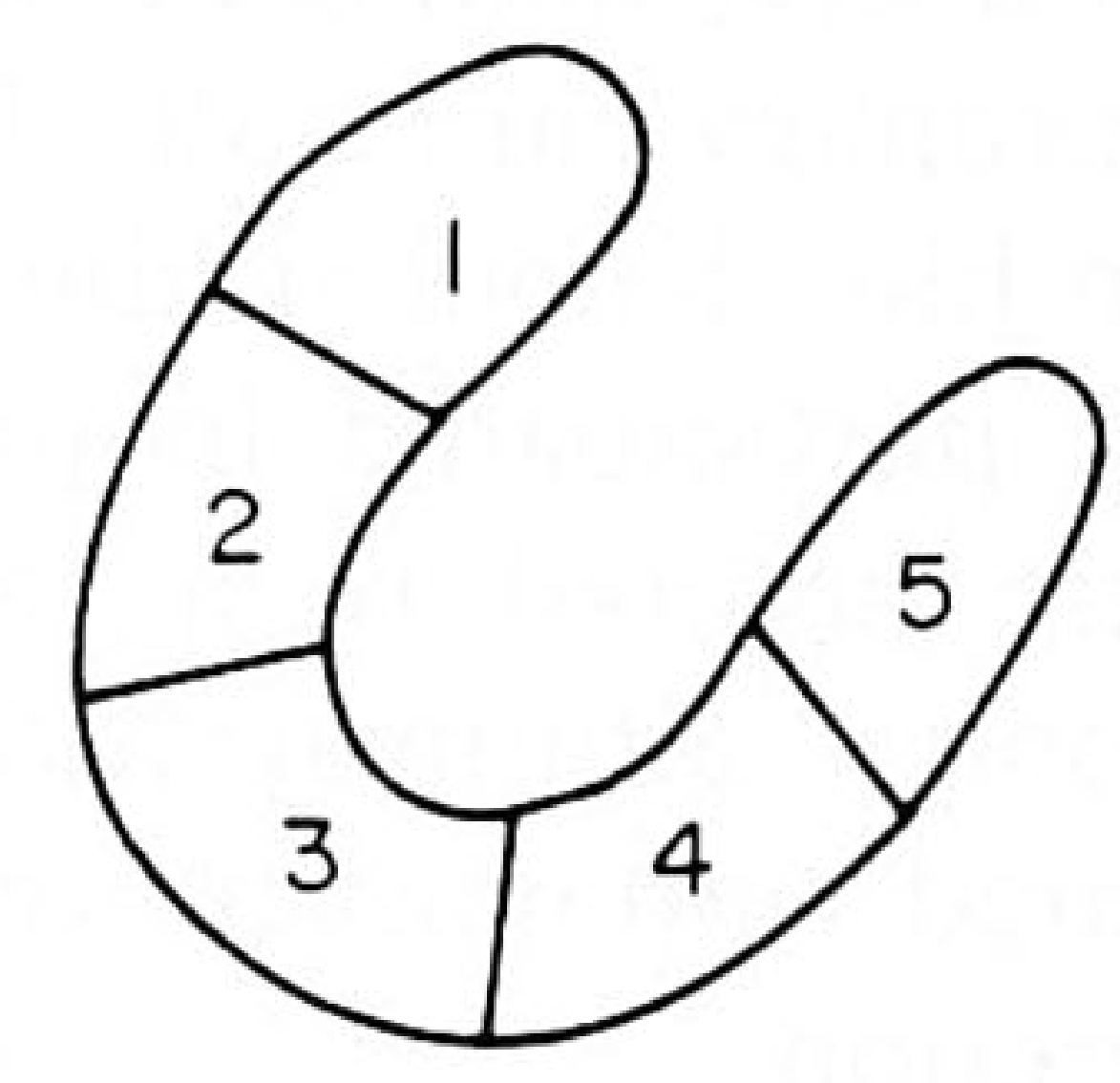

Figure 1 Regional thallium uptake was described in five regions in the anterior and LAO $65^{\circ}$ views and in three regions in the LAO $45^{\circ}$ view. In each region thallium uptake was described as $0=$ absent; $1=$ virtually absent; $2=$ reduced; $3=$ possibly reduced; $4=$ normal. intracoronary thrombolysis in myocardial infarction at the Thoraxcenter ${ }^{[7.8]}$ as well as the present randomized trial ${ }^{[3]}$ are presented in contributions to this issue of the European Heart Journal. Thallium scintigrams were made only if thallium, a gamma camera and necessary personnel were immediately available. The studies were omitted if the actual intervention with streptokinase would be delayed by more than 20 min because of the scintigraphy. Immediately upon admission approximately $1.5 \mathrm{mCi} \mathrm{Tl}^{201}$ was administered intravenously. Scintigrams were made 5 min after injection in 50 patients as presented in Table 1 . In 37 patients a left arterior oblique (LAO) $45^{\circ}$ and anterior view were made with 5 min of data collection. In 13 early patients other views were made: an anterior view only in three patients, anterior and LAO $65^{\circ}$ views in two patients and in five others LAO $45^{\circ}$ and LAO $65^{\circ}$ views, while all three views were obtained in three patients.

Either a Siemens Pho-gamma V, a Siemens LEM or a Ohio Nuclear mobile camera was employed. The scintigrams were repeated after the catheterization procedure or after approximately $3 \mathrm{~h}$ in the control group. All scintigrams were analysed by three independent observers using either the unprocessed Polaroid scintigrams or prints on X-ray film with $20 \%$ background subtraction ${ }^{[9]}$. Thallium uptake in the regions as indicated in Fig. 1 was classified as normal (4), possibly reduced (3), reduced (2), virtually absent (1) or absent (0). The scores from all three observers were added, thus resulting in a final score between 0 and 12 for each region. Since in some patients different views were recorded, data are presented as the percentage of 


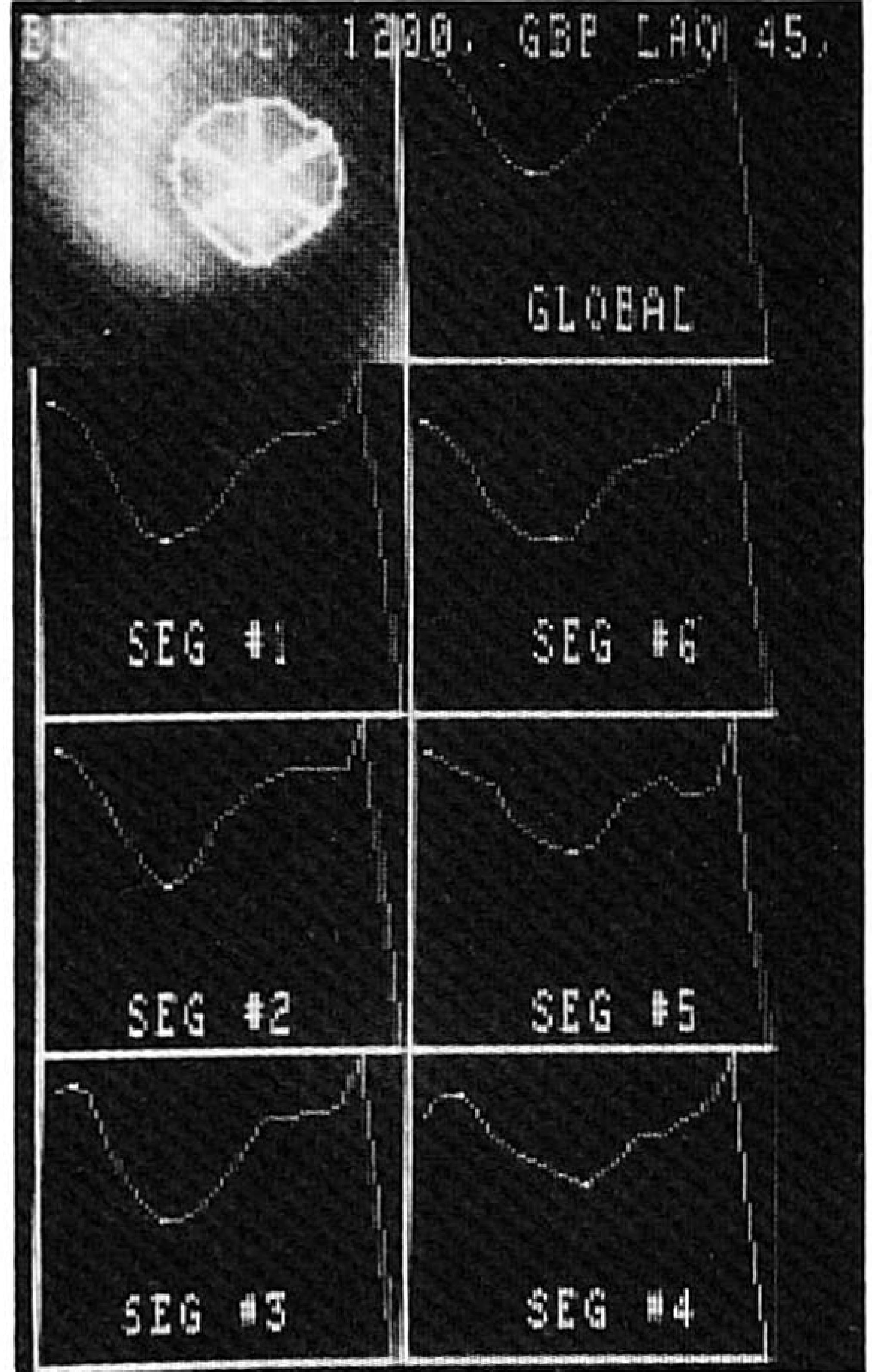

Figure 2 For computation or regional ejection fraction the left ventricle in the LAO $45^{\circ}$ view is divided into six segments of $60^{\circ}$ each. Left ventricular contours and background are determined automatically with the aid of computer programs developed at the Thoraxcenter ${ }^{[9]}$.

the maximum score which would be obtained if all regions were normal.

Gated blood-pool scintigrams were made one to seven days after admission in 65 patients (Table 1 ). In 35 patients the study was done after one day, in 20 after two days, in seven after three days, in one after four days, in two after five days and in one after seven days. In 19 patients the scintigrams were repeated after 10 to 20 days. Multigraded scinti- grams were acquired in the $45^{\circ} \mathrm{LAO}$ view after in vivo labelling of the red blood cells with $15 \mathrm{mCi}$ of Tc $99 \mathrm{~m}$. Acquisition was performed during a 6-min period with a Searle Pho-gamma V camera or an Ohio nuclear mobile camera equipped with a low energy all purpose collimator.

The data (20 frames in each cardiac cycle) were processed as recently described ${ }^{10]}$ through an automated procedure implemented on a DEC Gamma 11 computer system. Briefly, after detection of the left ventricular boundaries in the end-diastolic and in the end-systolic frames, the maximal and minimal counts in corresponding regions of interest were corrected for background activity. The ejection fraction was then calculated.

This method is characterized by a small average difference of 0.01 between scintigraphic and angiocardiographic ejection fractions with a standard deviation of 0.09 , and by an intra- and inter-observer variability of 0.03 (standard error of the estimate ${ }^{[10]}$. In nine normal subjects, the lower limit of left ventricular ejection fraction was 0.54 (range 0.54 to 0.83 , mean $0.69 \pm 0.09$ ). Regional ejection fraction was computed in six segments of the left ventricle as illustrated in Fig. 2.

\section{Results}

\section{THALLIUM SCINTIGRAPHY}

All patients in the present series were confirmed as having a myocardial infarction as shown by subsequent analysis of ECG changes and serum enzymes. They all had abnormal initial scintigrams, with a thallium uptake between 42 and $96 \%$
Pilot studies

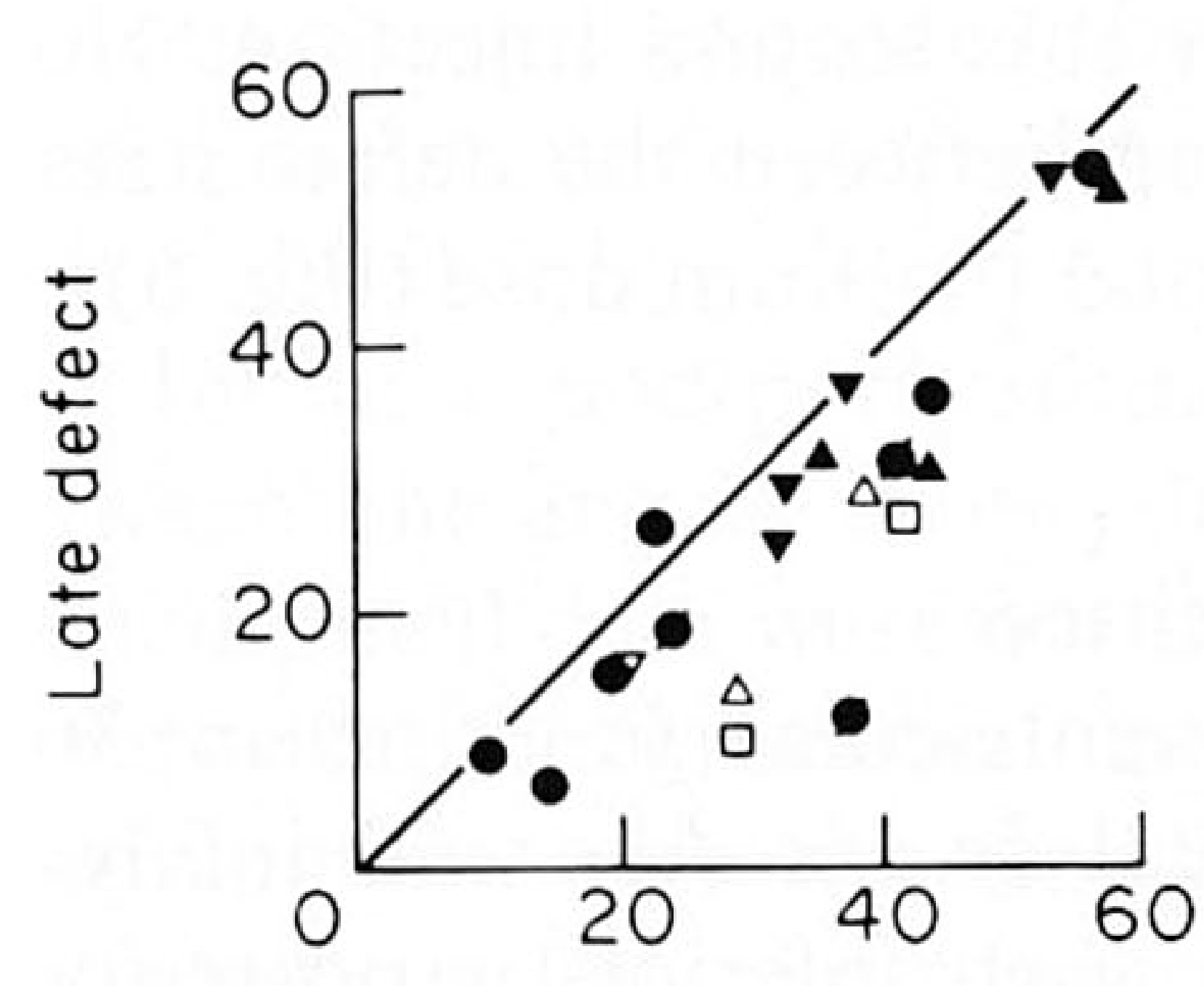

Randomized trial

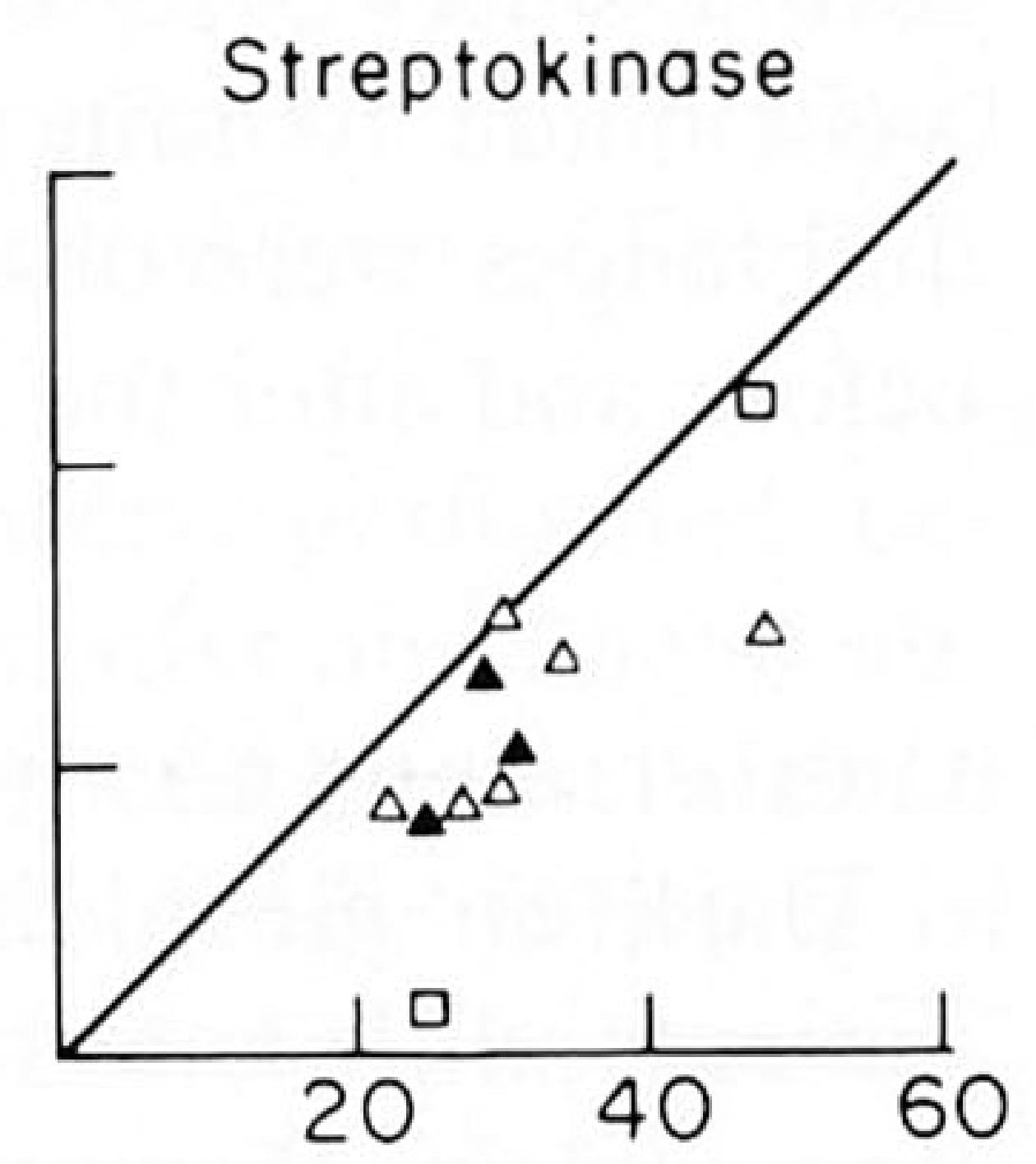

Control

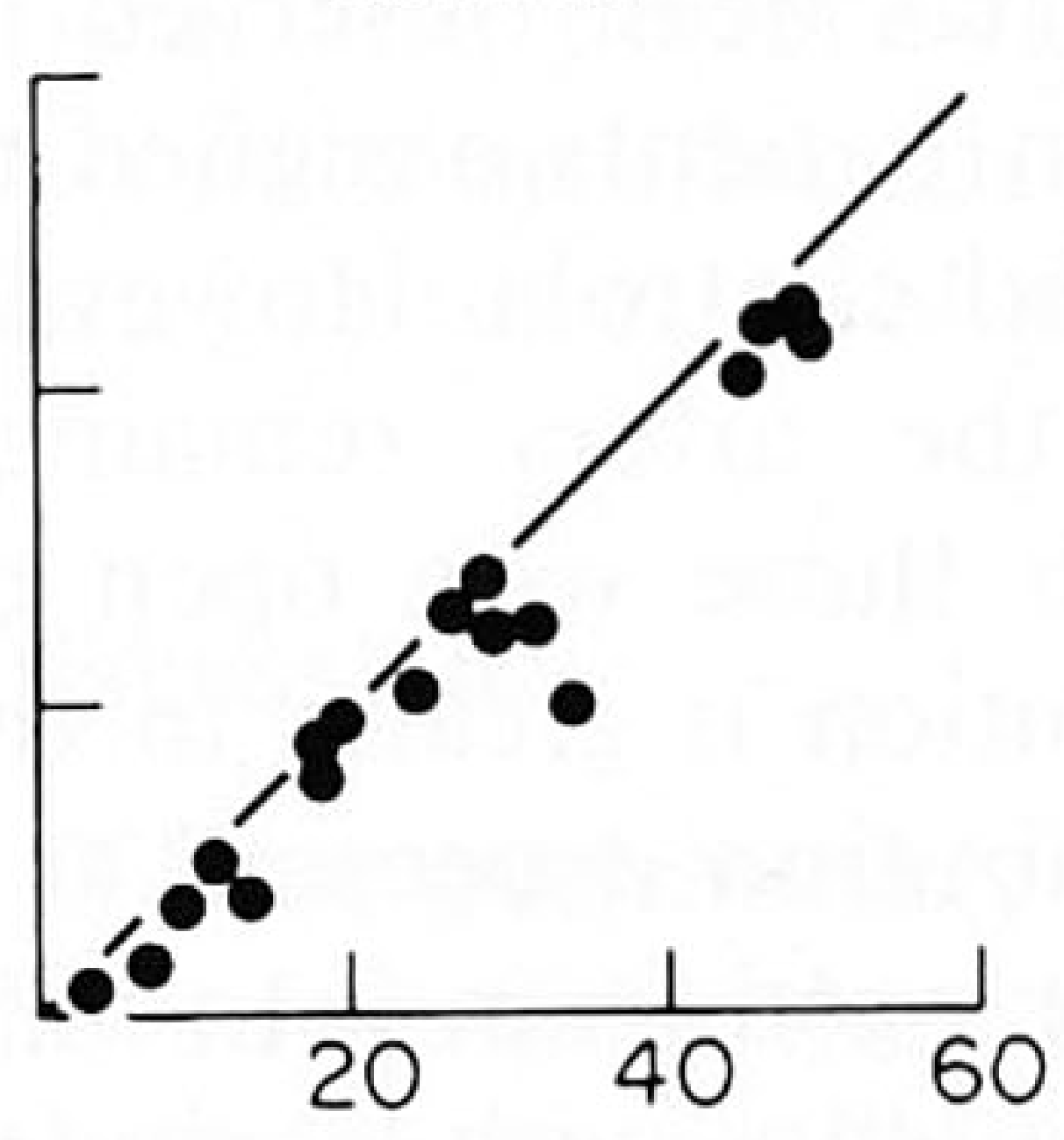

Initial defect (\% of total score)

Figure 3 Comparison of the extent and the degree of thallium defects upon admission (initial defect) and the defect after attempted thrombolysis, or after $3 \mathrm{~h}$ conventional therapy (late defect). $\square=$ Patients with subtotal occlusion at angiography; triangles are patients with an occluded coronary artery which either remains occluded $(\boldsymbol{\Delta \nabla})$ or opens after the intervention $(\Delta \nabla) ; \boldsymbol{\theta}=$ patients randomized to conventional treatment or $\boldsymbol{\phi}=$ patients who refused the intervention. $\mathbf{\Delta} \Delta=$ Streptokinase; $\nabla \nabla=$ urokinase/nifedipine. 


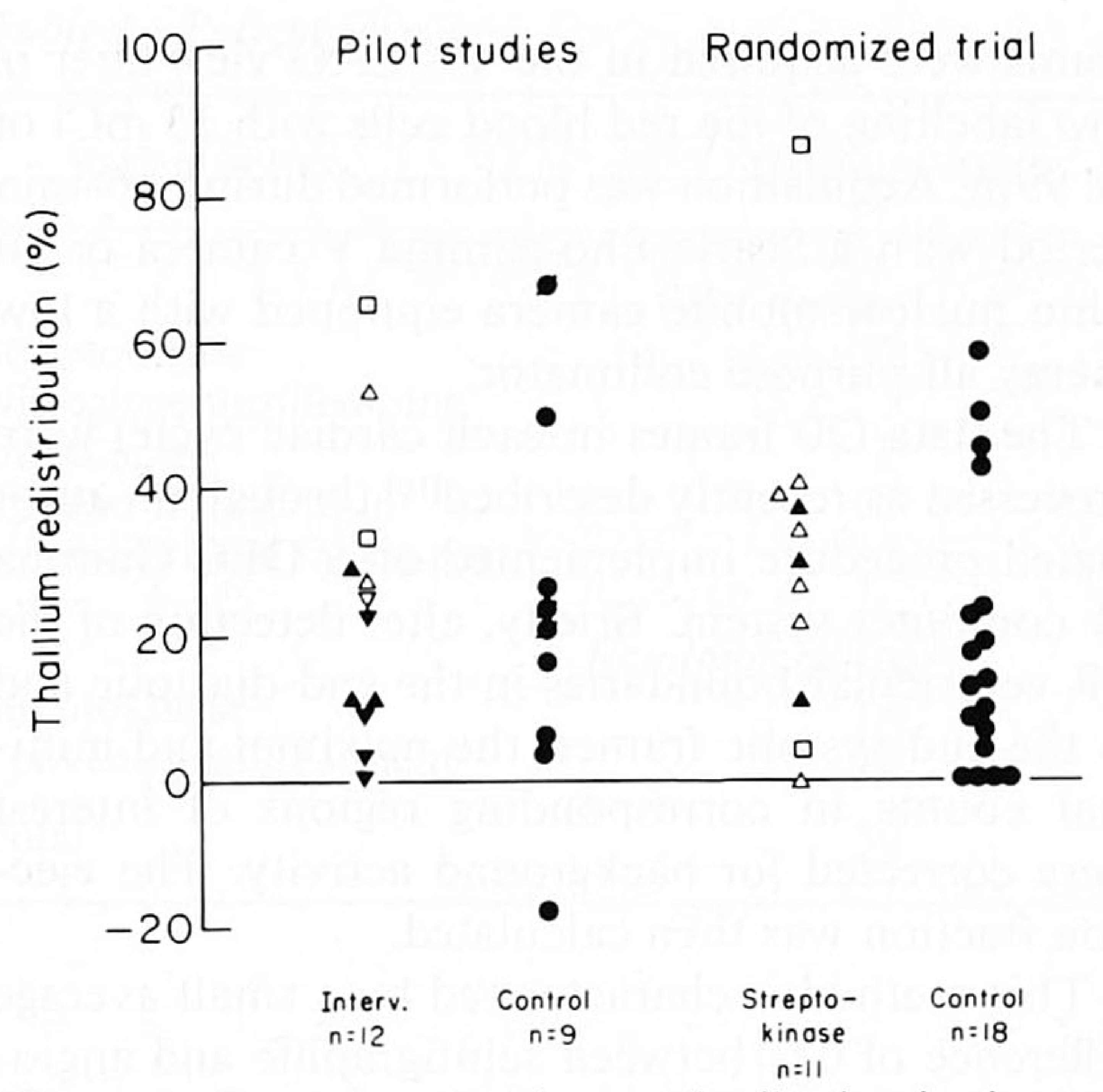

Figure 4 Percentage thallium redistribution in the same patients as Fig 3. In the pilot studies patients with open arteries have a greater degree of redistribution than patients with permanently occluded arteries. No differences are apparent in the randomized trial. [Data from various interventions in the pilot studies have been combined (interv.).] $\Delta \nabla=$ recanalization; $\boldsymbol{\Delta} \boldsymbol{\nabla}=$ no recanalization; $\square=$ subtotal occlusion; $\bullet=$ control; $\boldsymbol{\phi}=$ refuser.

of the maximal score. Thus the estimated defects ranged from 4 to $58 \%$ (Fig. 3). There were no major differences in the size of the initial defects in the various treatment groups.

Some degree of thallium redistribution occurred in 43 out of the 50 patients. In one patient, a small extension of the defect was reported while in six patients the early and late scintigrams were the same (Fig. 3 and 4). Redistribution occurred both in patients with successful thrombolysis and in patients in whom the artery remained occluded. So far no significant difference has been observed in the randomized trial between patients assigned to streptokinase intervention and controls. However, if all patients in whom the artery remained occluded are compared with those with open or recanalized arteries redistribution is greater in the latter group (Fig. 5). Redistribution expressed as a fraction of the initial defect ranged from 0 to $37 \%$ (mean 17, s.d. 12) in 10 patients with occluded arteries and from 0 to $87 \%$ (mean 35, s.d. 24) in 13 patients with open or recanalized arteries $(P<0.05)$. This supports the concept that recanalization of an occluded coronary artery results in partial myocardial salvage in some patients, if it is assumed that $\mathrm{Tl}$ uptake takes place in viable myocardial cells.
Table 2 Left ventricular ejection fraction

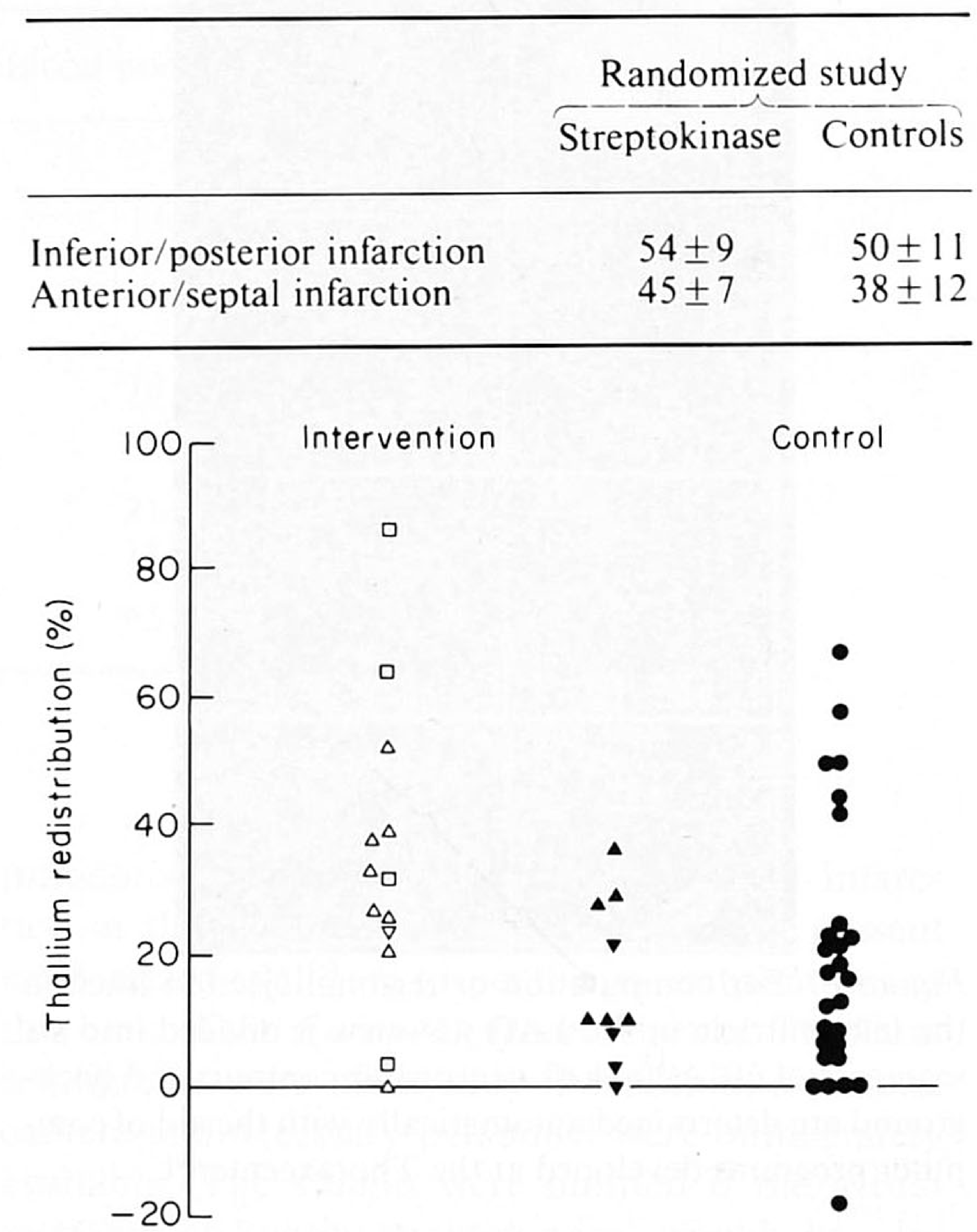

Figure 5 Similar data as in Fig. 4, when all patients are combined. Thallium redistribution in patients with open or recanalized arteries is greater than in patients with occluded arteries. However, a similar redistribution is observed in part of the patients in the contrl group. Symbols as in Fig. 4.

The second series of scintigrams were made 1 to $2 \mathrm{~h}$ after recanalization. In order to test whether this interval was appropriate, a second thallium injection $(1.5 \mathrm{mCi})$ was given in six patients after the second series of scintigrams. A third series of images were made $10 \mathrm{~min}$ after this second injection. No differences were observed between the defect sizes before and after the second thallium dose (Fig. 6).

\section{LEFT VENTRICULAR FUNCTION}

Data on global left ventricular function in 30 patients with anteroseptal or anterior wall infarction and in 35 patients with inferior or posterior wall infarction are presented in Fig. 7. Ejection fraction ranged from 13 to $74 \%$. Ejection fractions in patients with anterior wall infarction (mean $40 \%$, s.d. $12 \%$ ) were lower than those in patients with inferior wall infarction (mean 51\%, s.d. 11\%).

In the pilot studies no differences were observed between patients with open or occluded arteries 

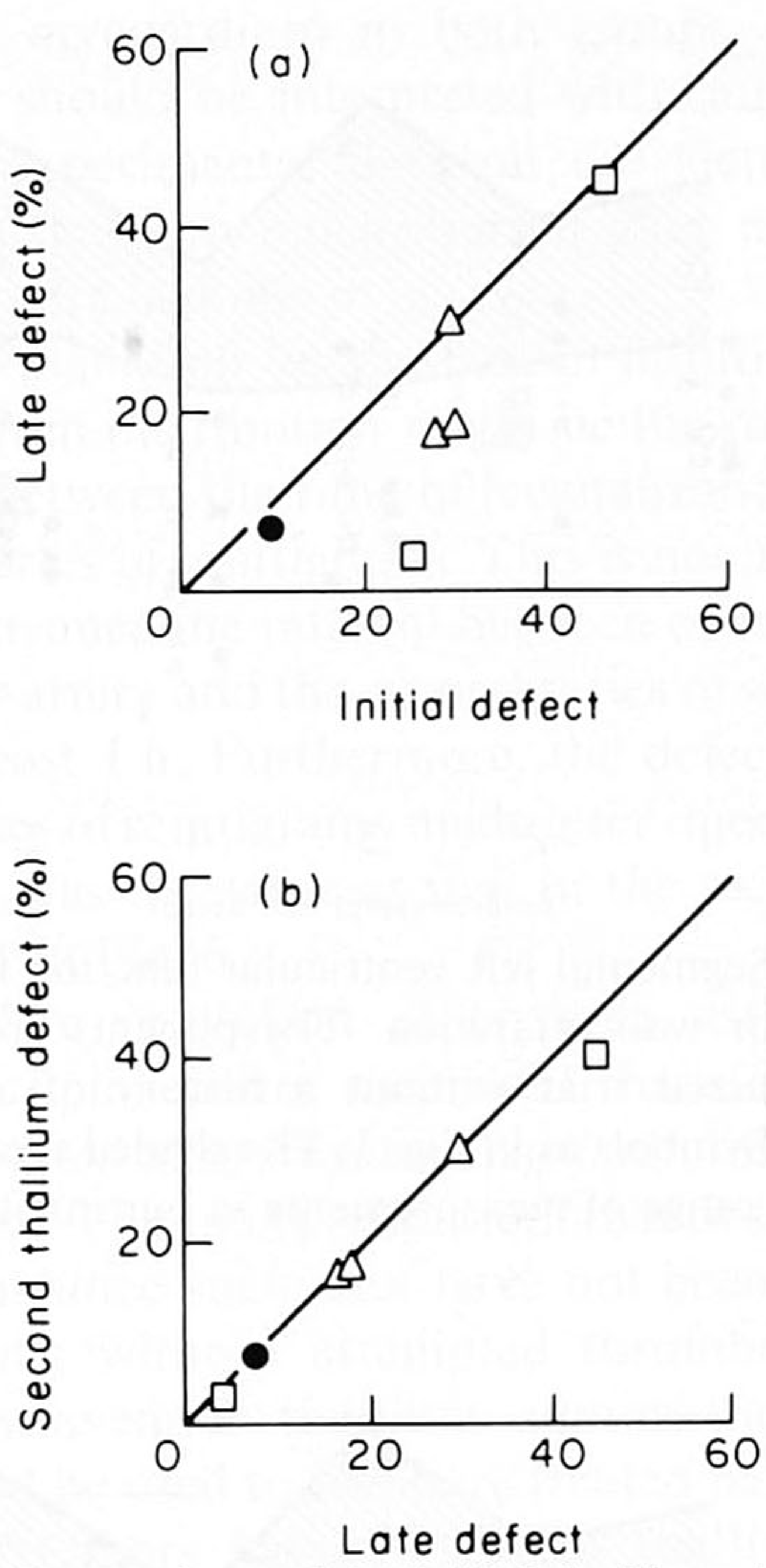

Figure 6 Comparison of the initial thallium defect at admission and the defect after intervention (late defect), after (a) the first dose of thallium as well as (b) comparison of the late defect and the thallium distribution defect after a second dose of thallium given intravenously. There is no difference between the late defect, after intervention, and the defect after the second injection.

after the intervention (Table 2). In the randomized trial also, no difference was observed between patients with inferior wall infarction assigned to streptokinase compared to controls. However, in the smaller series of patients with anterior wall infarction, left ventricular ejection fraction after streptokinase exceeded the measurement obtained in patients under conventional treatment (Table 2 , $P<0.05$ ).

Initial blood-pool studies were performed between one and seven days of admission. The aforementioned data were not influenced by the interval between the infarction and the study. This is in agreement with the finding that no changes occurred in left ventricular ejection fraction early compared with those determined 10 to 20 days after the acute episode (Fig. 8).

Segmental left venttricular function was analysed in 26 patients from the randomized trial who had no history of a previous infarction. Seven other patients had such a history while in six cases segmental function could not be analysed for technical
Pilot studies

Randomized trial

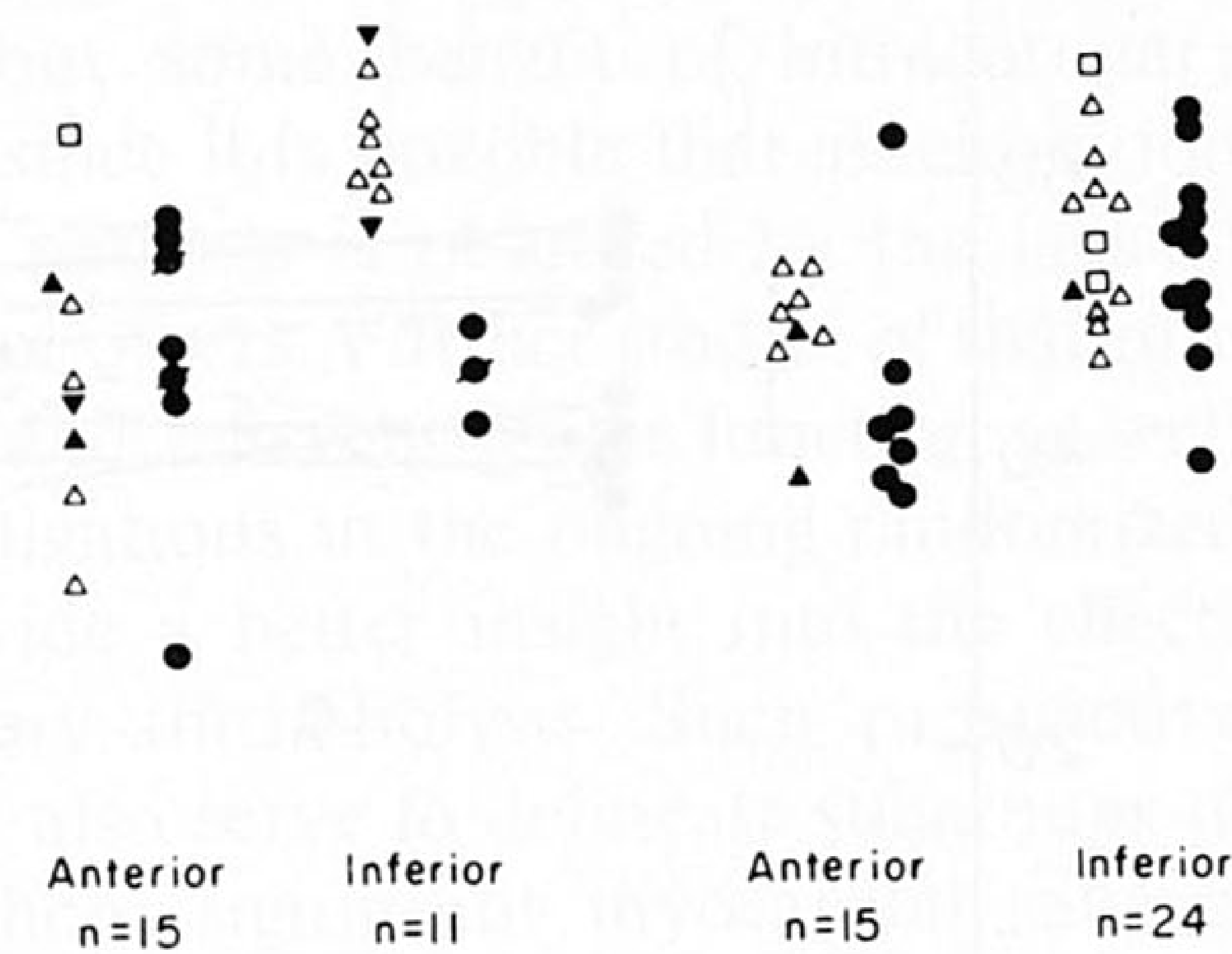

Figure 7 Left ventricular ejection fraction measured by gated blood-pool scintigraphy between one and seven days after admission. Symbols as in Fig. 3. Ejection fraction in patients with anterior wall infarction is lower than in patients with inferior wall infarction. In the randomized trial, patients with anterior wall infarction after streptokinase show a higher ejection fraction than control patients.

problems with the magnetic tape used for data storage. In Fig. 9 segmental ejection fraction is presented in 15 patients with inferior wall infarction. As expected, the greatest reduction of segmental ejection fraction was present in the apical segments. No differences were observed between patients with successful or attempted thrombolysis and controls.

Similar data from 11 patients with anterior wall infarction are presented in Fig. 10. Here the greatest reduction of regional ejection fraction was present in the antero-septal regions. In these regions no differences are observed between control patients and those treated with streptokinase. However, in the apical and postero-lateral regions segmental ejection fraction after successful thrombolysis is greater than in four control patients.

\section{Discussion}

These preliminary observations do not support the suggestion that extensive myocardial salvage can be obtained after successful recanalization with streptokinase. Thallium scintigraphy before and after the procedure did show redistribution in most patients, including those in whom the artery remained occluded and those were treated by conventional methods. Similarly, global and regional left ventricular function showed little difference between the groups. 


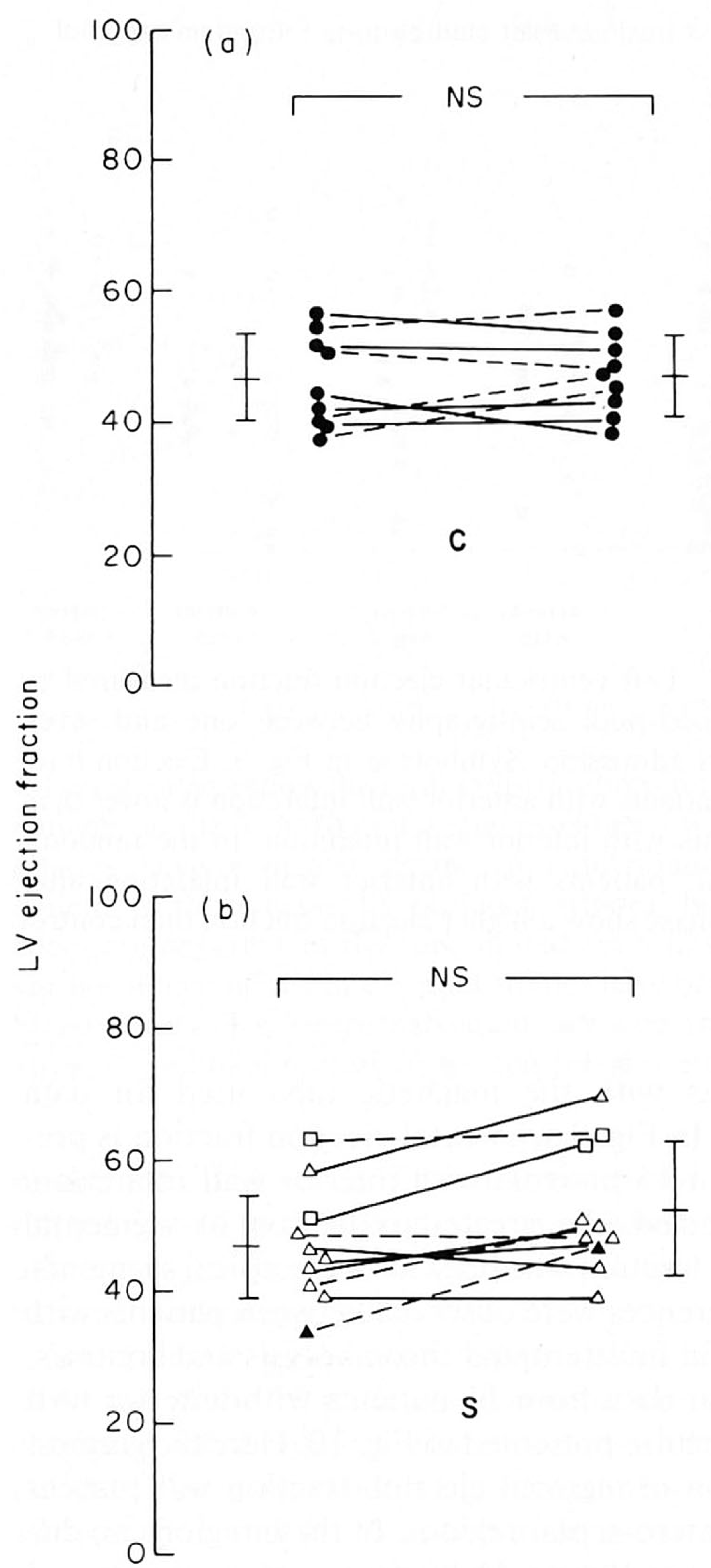

Figure 8 Left ventricular ejection fraction obtained between one and seven days after admission (left-sided symbols in both a and b) and 10 to 20 days after admission (right-sided symbols). (a) Patients treated by conventional methods $(C, n=9)$; (b) patients with attempted thrombolysis $(\mathrm{S}, \mathrm{n}=10)$. Symbols as in Fig. $3 .-=$ Patients with inferior wall infarction; $---=$ measurements of patients with anterior wall infarction. There is no significant difference between early and late ejection fractions in either group.

It is likely that the delay between the onset of symptoms and thrombolysis is a major determinant of the result of the intervention. Accordingly this interval should not be prolonged by additional procedures. Nevertheless in an effort to evaluate the efficacy of that procedure, it was decided to perform thallium scintigraphy before the catheterization

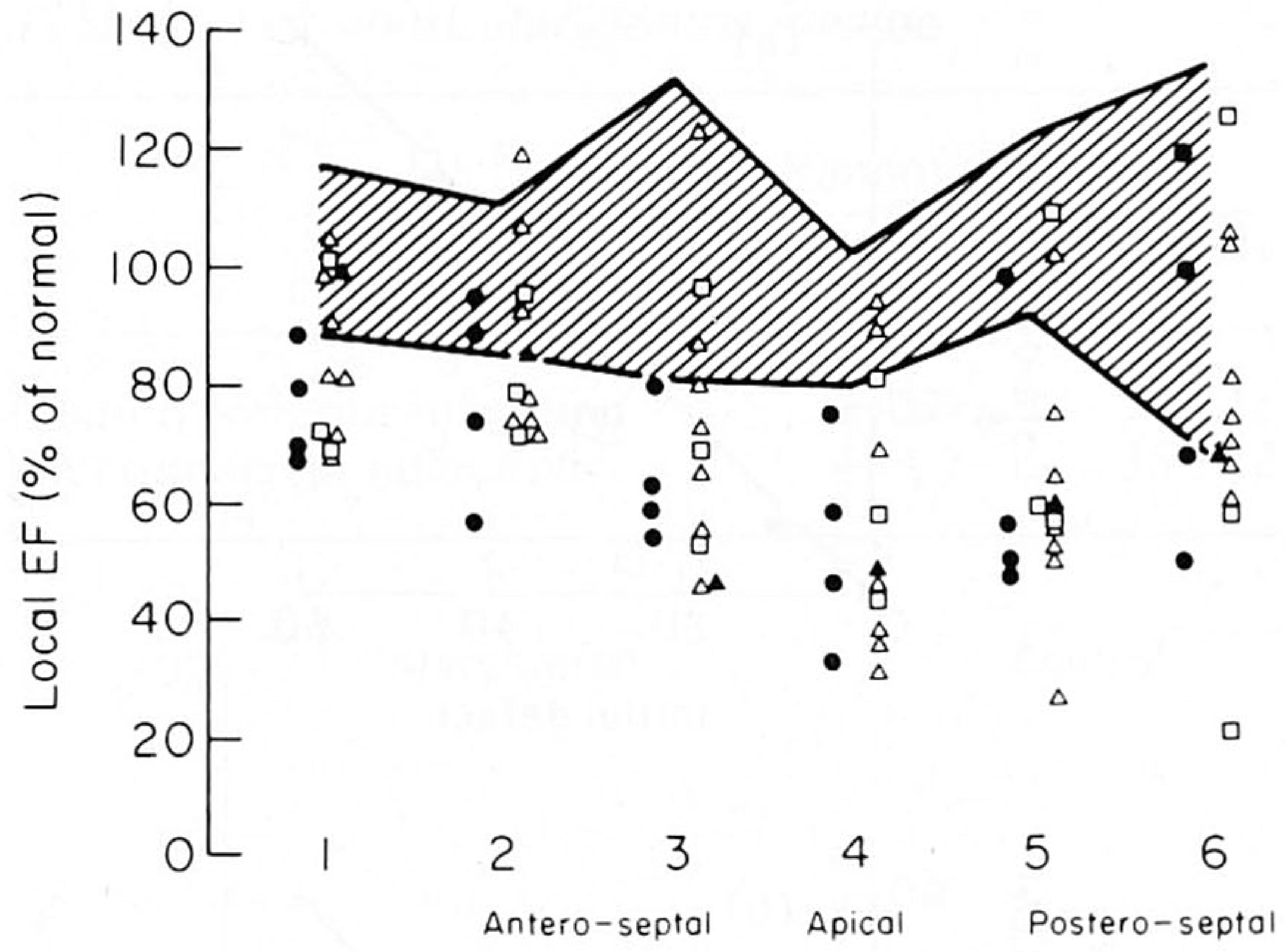

Figure 9 Segmental left ventricular function in patients with inferior wall infarction. The patients are those in the randomized trial without a history of a previous infarction. Symbols as in Fig. 3. The shaded area indicates the normal range of measurements in our institution.

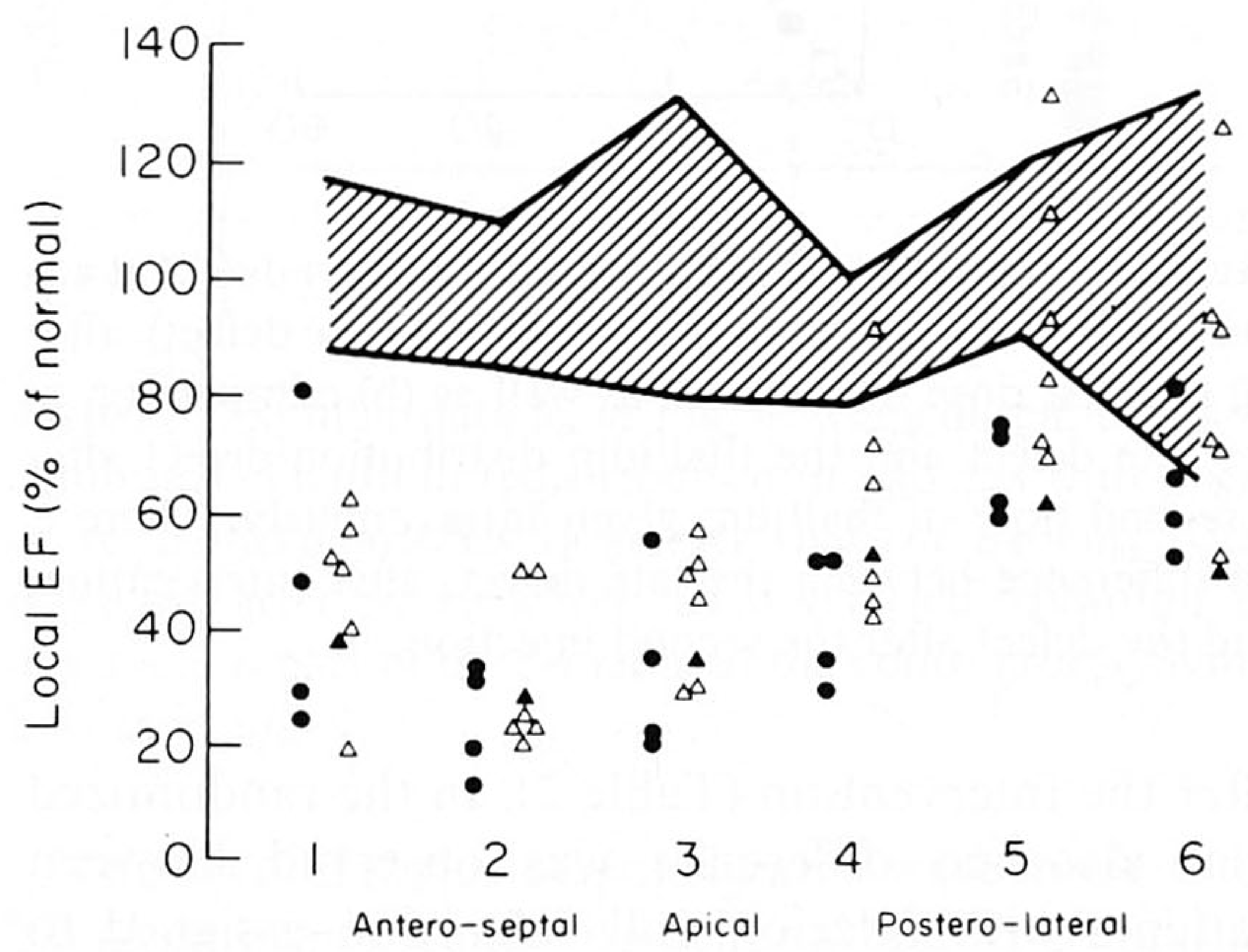

Figure 10 Segmental left ventricular function in patients with anterior wall infarction. See legend for Fig. 9.

itself in those patients in whom the scintigrams could be made during the time needed to prepare the catheterization laboratory. Thallium scintigrams were omitted when this would delay the whole procedure by more than $20 \mathrm{~min}$. Typically this occurred when the catheterization laboratory was available while the gamma camera was in use for other purposes.

It was our reasoning that thallium scintigraphy would be an excellent way to compare the initial size of the diseased myocardium in patients assigned to streptokinase intervention to that in the control group. Furthermore thallium scintigraphy provided a measure of the recovery of previously 
ischemic myocardium in both groups. However, our data should be interpreted with caution since detailed experimental data on the factors which influence thallium redistribution after myocardial infarction are lacking.

One explanation for the lack of improvement of the thallium distribution might be the rather short interval between the time of recanalization and the second series of scintigrams. This is not a likely explanation since the interval between opening of the coronary artery and the second series of scintigrams was at least $1 \mathrm{~h}$. Furthermore, the defect size in a third series of scintigrams made after injection in six patients, was the same as that in the second series as shown in Fig. 6.

Complete resolution of an area with reduced thallium uptake after successful thrombolysis has been reported after intracoronary administration of thallium ${ }^{6]}$. The interpretation of that observation is uncertain since such data have not been described in patients without attempted thrombolysis. We chose intravenous thallium administration since this could be used to compare treated patients with controls. Others have compared thallium scintigrams at admission with scintigrams made two weeks later ${ }^{[11]}$. However, resolution of an area with reduced thallium uptake after such a period occurs frequently, even when no attempts at myocardial salvage are made ${ }^{[12]}$. Reduto et al.[5] described improved global LV ejection fraction between admission and discharge in nine out of 20 patients with recanalization after streptokinase. In our series, global ejection fraction in patients with antero-septal infarction measured one to four days after thrombolysis was indeed higher than in controls. However, no differences were observed in patients with inferior wall infarction. Furthermore, no changes occurred between early measurements and those 10-20 days after admission.

Segmental wall motion was impaired in all regions in most patients studied in this manner. This was due in part to overlap of ventricular segments in the LAO view. Wall motion analysis in the gated RAO scintigram is not suitable since both ventricles overlap in that view. Nevertheless the patterns of regional ejection fraction in patients with inferior wall or antero-septal infarction differed markedly. Since the groups are small, the data should be interpreted with caution. However, in patients with anterior wall infarction, ejection fractions in the apical and postero-lateral regions in patients with open arteries are higher than in controls. If this could be confirmed in a larger series, it may indicate that wall motion in the border zone of an infarct can indeed be improved by thrombolysis after intracoronary streptokinase, as was shown by Hooghoudt et al.[8].

The largely negative findings in the present study do not rule out some benefit of intracoronary thrombolysis, since it is possible that amelioration in part of the patients is obscured by the lack of improvement of others. Further studies of thallium redistribution and left ventricular function as well as other investigations in the ongoing randomized trial will provide a better insight into the effects of intracoronary thrombolysis. Such prospective studies should also serve to delineate subgroups of patients in whom significant myocardial salvage can be achieved and other subgroups in whom the procedure is ineffective and therefore should not be attempted at all.

\section{References}

[1] Wood MA, Spores J, Notske R, Mouser LT, Burroughs R, Golden MS, Lang HT. Prevalence of total coronary occlusion during the early hours of transmural myocardial infarction. New Engl J Med 1980; 303: 897-902.

[2] Merx W, Dorr R, Rentrop P, et al. Evaluation of the effectiveness of intracoronary streptokinase infusion in acute myocardial infarction: postprocedure management and hospital course in 204 patients. Am Heart J 1981; 102: 1181-7.

[3] Fioretti P, Simoons ML, Serruys PW, Brand M van den, Fels PW, Hugenholtz P. Clinical course after attempted thrombolysis in myocardial infarction. Results of pilot studies and preliminary data from a randomized trial. Eur Heart J 1982; 3: 422-32.

[4] Rentrop P, Blanke H, Karsch R, et al. Changes in left ventricular function after intracoronary streptokinase infusion in clinically evolving myocardial infarction. Am Heart J 1981; 102: 1188-93.

[5] Reduto LA, Freund GC, Gaeta JM, Smalling RW, Lewis B, Gould L. Coronary artery reperfusion in acute myocardial infarction: beneficial effects of intracoronary streptokinase on left ventricular salvage and performance. Am Heart J 1981; 102: $1168-77$.

[6] Schofer J, Mathey D, Kuck KH, Montz R, Bleifeld W. Early assessment of salvaged myocardium after coronary artery recanalization by sequential intracoronary thallium scintigraphy. Am J Cardiol 1982; 49: 962. (Abstract).

[7] Serruys, PW, Brand M van den, Hooghoudt TEH et al. Coronary recanalization in acute myocardial infarction: immediate results and potential risks. Eur Heart J 1982; 3: 404-15.

[8] Hooghoudt TEH, Serruys PW, Reiber JHC, Slager CJ, Brand $M$ van den, Hugenholtz PG. Recanalization of the occluded coronary artery in patients with acute myocardial infarction: influence on left ventricular function. Eur Heart J 1982; 3: 416-21. 
[9] Lie SP, Reiber JHC, Simoons ML, Withagen AJA, Gerbrands JJ. Quantification of the location and extent of defects in thallium-201 uptake and redistribution patterns. Proc Comp Cardiol 1979: 307-10.

[10] Gerbrands JJ, Hoek C, Reiber JHC, Lie SP, Simoons ML. Minimum cost contour detection in technetium-99m gated cardiac blood pool scintigrams. Proc Comp Cardiol, 1981.
[11] Maddahi J, Ganz W, Geft I, et al. Intracoronary thrombolysis in acute myocardial infarction: assessment of efficacy by thallium-201 scintigraphy. Am J Cardiol 1982; 49: 973. (Abstract)

[12] Wackers FJ, Sokole E, Samson G, et al. Value and limitations of thallium-201 scintigraphy in the acute phase of myocardial infarction. New Engl J Med 1976; 295: 1 . 